\title{
FcyRIIA-131 asociado a casos severos de dengue en Honduras
}

Cynthia Rodríguez, Ivette Lorenzana de Rivera

\section{RESUMEN}

El dengue es una enfermedad de importancia a nivel mundial, por eso recientemente se ha incrementado el interés en buscar los factores genéticos en el huésped asociado a la severidad de la enfermedad, para poder entender más sobre la patogénesis del dengue.

Se investigó si polimorfismos de nucleótido simple (SNP) en genes que codifican para DC-SIGN1-336, el receptor Fc (FcyRIIA) y el receptor de la vitamina D (VDR), están asociados con el dengue severo y si en el grupo de estudio la severidad del dengue se asocia a las infecciones secundarias. Para esta investigación se estudió a un total de 200 participantes con dengue, quienes fueron investigados en Tegucigalpa; 100 casos de dengue clásico y 100 de dengue hemorrágico, clasificados de acuerdo a los criterios de la OMS 2007.

La genotipificación se realizó utilizando PCR RFLP comparado con el ensayo iPLEX (SEQUENOM ® Inc. EE.UU.). Un aumento significativo de riesgo de enfermedad severa se observó en FcyRIIA-131, en los portadores de los genotipos CC versus $\mathrm{TC}(\mathrm{Chi} 2=5.29, \mathrm{P}=0.02, \mathrm{OR}=2.22)$. El alelo $\mathrm{G}$ de la variante $\mathrm{DC}-\mathrm{SIGN}-336$ no se asoció con dengue severo, para el VDR-352 la frecuencia del genotipo CC en comparación con el TC muestra una tendencia a aumentar en las formas severas respecto a las formas leves de la enfermedad $\left(\mathrm{Chi}^{2}=3.36, \mathrm{P}=0.06, \mathrm{OR}=0.35\right)$. Estos datos preliminares aportan nuevos conocimientos sobre el papel de los factores genéticos en el dengue; el conocimiento de estos SNP asociados con dengue proporcionará información sobre los posibles mecanismos de la patogénesis y protección.

Palabras claves: polimorfismos de nucleótido simple (SNP), genotipificación, dengue, VDR, FcyRIIA, DC-SIGN, alelo, genotipo, infección primaria y secundaria.

\footnotetext{
${ }^{1}$ Universidad Nacional Autónoma de Honduras. Facultad de Ciencias, Escuela de Microbiología. Correo electrónico: cynthiasub@yahoo.com; ivettelorenzana@yahoo.com
} 


\section{ABSTRACT}

Dengue is a disease of worldwide importance. To understand more about the pathogenesis of dengue the interest in the search for genetic factors in the host has recently increased.

We investigated whether single nucleotide polymorphisms (SNPs) in genes coding for DC-SIGN, Fc receptor (FcyRIIA) and vitamin D receptor (VDR) are associated with severe dengue and whether in this study group the severity of dengue is associated with secondary infections. A total of 200 cases of dengue patients were investigated in Tegucigalpa, Honduras, 100 cases of classic dengue and 100 cases of dengue hemorrhagic classified according to $2007 \mathrm{WHO}$ criteria.

Genotyping was performed using PCR-RFLP and additionally this technique was compare to the ¡PLEX assay (SEQUENOM $®$ Inc. USA). A significantly increased risk of severe disease was observed in FcyRIIA in carriers of genotype CC versus $\mathrm{TC}(\mathrm{Chi} 2=5.29, \mathrm{P}=0.02, \mathrm{OR}=2.22)$. The $\mathrm{G}$ allele variant of the DC-SIGN1-336 was not associated with severe dengue disease. The VDR genotype frequency of CC genotype compared whit CT scan shows a tendency to increase in severe forms compared to mild forms of the disease $\left(\mathrm{Chi}^{2}=3.36, \mathrm{P}=0.06, \mathrm{OR}=0.35\right)$. These preliminary data provide new insights into the role of genetic factors in dengue; knowledge of more SNPs associated with dengue will provide information on possible mechanisms of pathogenesis and protection.

Key words: single nucleotide polymorphisms (SNP), Genotyping, Dengue, VDR, FCYRIIA, DCSIGN, primary and secondary infection.

\section{INTRODUCCIÓN}

Las infecciones con el virus del dengue son una causa importante de morbilidad y mortalidad en zonas urbanas y semiurbanas de las regiones tropicales y subtropicales del mundo. El virus es transmitido principalmente por el vector Aedes aegypti, ampliamente distribuido en estas zonas. Globalmente, se reporta un estimado de 50 a 100 millones de casos de dengue clásico (DC) y 250,000 500,000 casos de dengue hemorrágico (DH) anualmente.

Las personas con síntomas de dengue desarrollan generalmente una fiebre indiferenciada o dengue clásico, que se caracteriza por fiebre, dolor de cabeza, dolor articular y muscular, erupción maculopapular y en algunos casos puede presentar hemorragia leve y un recuento bajo de plaquetas. 
El dengue hemorrágico, la forma más grave de infección por dengue, se produce en una minoría de pacientes y se define por la fiebre, hemorragia, trombocitopenia y extravasación de plasma. Este último se atribuye a un aumento en la permeabilidad vascular y se manifiesta por los valores de hematocrito elevado, hipoproteinemia 0 derrames en las cavidades serosas, que en los casos más complicados puede llevar al síndrome de choque por dengue (SCD).

Los mecanismos fisiopatológicos exactos responsables de estos fenómenos son todavía inciertos. La observación epidemiológica de que el dengue hemorrágico se presenta principalmente en personas experimentando una infección secundaria de dengue, ha conducido a la teoría de amplificación dependiente de anticuerpos (ADA). Según esta hipótesis, anticuerpos preexistentes no neutralizantes presentes durante una infección heterotípica secuencial del virus, facilitan su entrada y replicación en el linaje de células monocitos/macrófagos. Sin embargo, otros estudios también sugieren que la virulencia de la cepa podría ser un factor crucial para el desarrollo de dengue hemorrágico.

En este contexto, tanto factores del virus como del huésped, podrían ser de suma importancia en el resultado final de la infección. Sin embargo, en las zonas endémicas, solo una proporción relativamente pequeña de las personas con infecciones secuenciales desarrolla dengue hemorrágico. Esto podría indicar que hay factores de resistencia o susceptibilidad en el huésped que operan en los individuos infectados.

Este tipo de genes se puede encontrar dentro del complejo antígeno leucocitario humano (HLA), los que están codificados en el complejo mayor de histocompatibilidad (MHC) clase I y II. Estas moléculas HLA participan en la inducción de respuesta inmune mediante la presentación de péptidos a los linfocitos CD4+ y CD8+. Estudios anteriores en Tailandia y Cuba reportan ciertos alelos (formas alternativas de un gen que ocupan la misma posición en el genoma) de clase I del complejo HLA, asociados con la resistencia o susceptibilidad al dengue hemorrágico. Alelos HLA de clase II, sin embargo, han sido asociados a la severidad del dengue en infecciones primarias, igualmente con otras enfermedades. Algunos de los genes candidatos incluyen CD209 (DC-SIGN), VDR, el receptor Fcyll, TNF-a, IL-10, HLA-A, HLA-B, TAP1, TAP2 y CTLA-4, los cuales han demostrado asociación con dengue hemorrágico o dengue clásico.

\section{METODOLOGÍA}

Se llevó a cabo un estudio retrospectivo de casos y controles. Un total de 200 
pacientes con dengue fueron captados en Tegucigalpa; 100 casos de dengue clásico (como controles) confirmados por medio de laboratorio y 100 casos de dengue hemorrágico (como casos) clasificados como grado I y II, de acuerdo a los criterios de la OMS. La población consistió en individuos que tenían o habían tenido DC 0 evidencia serológica de infección con el virus del dengue (con o sin sintomatología asociada) e individuos que tenían o habían padecido $\mathrm{DH}$, certificados por la Comisión de Dengue de la Secretaría de Salud de Honduras. El estudio fue aprobado por el Comité de Ética de Investigaciones Biomédicas de la Unidad de Investigación Científica de la UNAH.

Con el fin de definir si las infecciones había sido primarias o secundarias, se analizaron los sueros de los participantes por determinación de anticuerpos lgG contra dengue, a través de ensayos imunoenzimáticos con pruebas comerciales (PanBio®, Brisbane, Australia), de acuerdo con las instrucciones y especificaciones del fabricante. Adicionalmente, se realizó la prueba de inhibición de aglutinación a algunos sueros que no se clasificaban claramente con las pruebas de ELISA, para la medición cuantitativa de anticuerpos totales contra dengue por medio de la titulación de sueros.

La genotipificación de los polimorfismos [DC-SIGN-336 (Dendritic Cell-Specific Intercellular Adhesión molecule-3-Grabbing Non-integrin) presente en células dendríticas, el receptor (FcyRIIA-131) ampliamente distribuido en todas las subclases de lgG y del receptor de vitamina D (VDR-352), quien se encuentra presente en la superficie de las células, se realizó mediante un PCR-RFLP (restriction fragment length polymorphism) que combina el PCR convencional y la digestión con enzimas de restricción.

Para dos de los tres polimorfismos se hizo una purificación de los productos de PCR, para luego proceder a la digestión. Esta técnica fue comparada con el ensayo iPLEX (Sequenom ${ }^{\circledR}$ Inc. EE.UU.). Para ambos ensayos, el ADN genómico fue extraído de muestras de sangre total de acuerdo a las instrucciones del fabricante de QIAmpADN de sangre mini kit (Qiagen ${ }^{\circledR}$, Santa Clarita, California, EE.UU.). La concentración de ADN se determinó utilizando el Nanodrop 2000 (Thermo Scientific $\circledR$, EE.UU.), para asegurarse de obtener la concentración adecuada para la genotipificación. EI PCR-RFLP se realizó en el Laboratorio de Virología de la UNAH y para el análisis en el IPLEX, el ADN fue enviado al Centro de Tecnología de Genética Analítica (AGTC) en Toronto, Canadá. Se utilizó la plataforma del Sequenom para genotipificación multiplex, que combina el procedimiento de PCR y espectrofotometría de masas (esquema 1). El rango de referencia para estos SNP utilizando esta plataforma es superior al $99.5 \%$. 
Para los análisis estadísticos se determinó la frecuencia de casos primarios y secundarios de $\mathrm{DC}$ y $\mathrm{DH}$, definidos por métodos serológicos. El análisis de los polimorfismos en los casos y controles obtenidos por la genotipificación se realizo a través de la prueba de chi cuadrado $\left(X^{2}\right)$, el valor $P$ y la razón de probabilidades $(O R)$ con un $95 \%$ de confianza, utilizando el programa SPSS (versión 11.5.1).

Esquema 1. Proceso del ensayo iPLEX (MassArrays) en la plataforma Sequenom

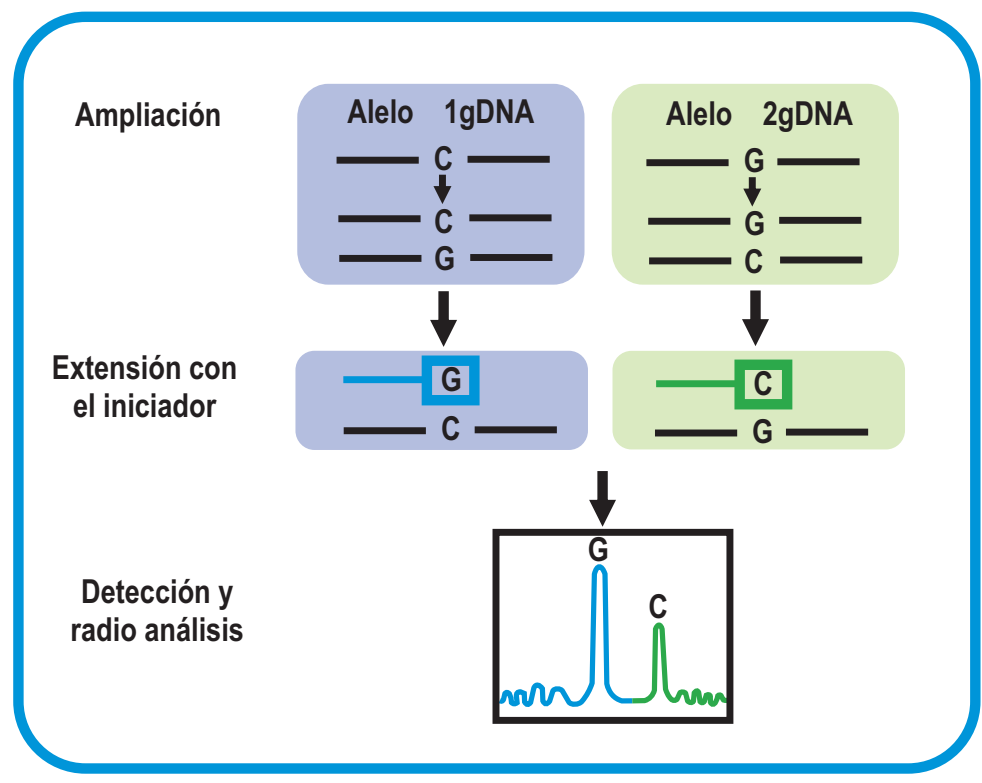

\section{RESULTADOS}

\section{Generalidades de la población en estudio}

Los participantes clasificados como DC (controles) y DH grado I y II, considerados los casos, todos fueron recolectados entre los años 2008 y 2009 en la ciudad de Tegucigalpa, Honduras. Los participantes estuvieron comprendidos entre las edades de 1 a 73 años; de estos, el $62 \%$ eran jóvenes entre 11 a 30 años de edad (gráfico 2) y el $60 \%$ de los participantes pertenecían al género femenino y el resto al masculino (ver gráfico1).

No se cuenta con información exacta de los serotipos virales que afectaron a la población del estudio, los serotipos circulantes reportados por la Secretaría de Salud durante ese periodo, fueron el DEN-1, DEN-2 y DEN- 4 . 
Gráfico 1. Distribución de la infección ( $\mathrm{DC}$ y $\mathrm{DH})$ por edad en la población en estudio $(n=200)$

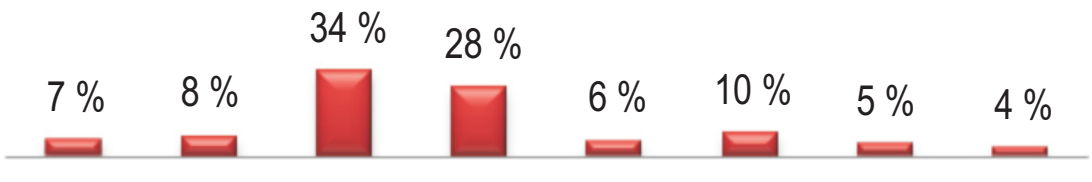

$$
\begin{aligned}
& \text { 1a } 5 \text { 6а } 10 \quad 11 \text { a } 2021 \text { a } 3031 \text { a } 4041 \text { a } 5051 \text { a } 60 \quad 61 \text { a } 73 \\
& \text { Edad en años }
\end{aligned}
$$

Clasificación de la infección por dengue

De acuerdo con el perfil serológico se encontró que un $78 \%$ de las infecciones eran secundarias (ver tabla 2). Se observaron frecuencias similares en las infecciones primarias y secundarias entre el dengue clásico y dengue hemorrágico (ver gráfico 2).

Tabla 2. Clasificación de las infecciones primarias y secundarias por dengue en los casos y controles

\begin{tabular}{|l|c|c|}
\hline \multicolumn{1}{|c|}{ Infecciones } & No. & Porcentaje \\
\hline Primarias & 43 & 21.5 \\
\hline Secundarias & 157 & 78.5 \\
\hline TOTAL & 200 & 100 \\
\hline
\end{tabular}

Gráfico 2. Distribución de las infecciones primarias y secundarias entre dengue clásico y dengue hemorrágico

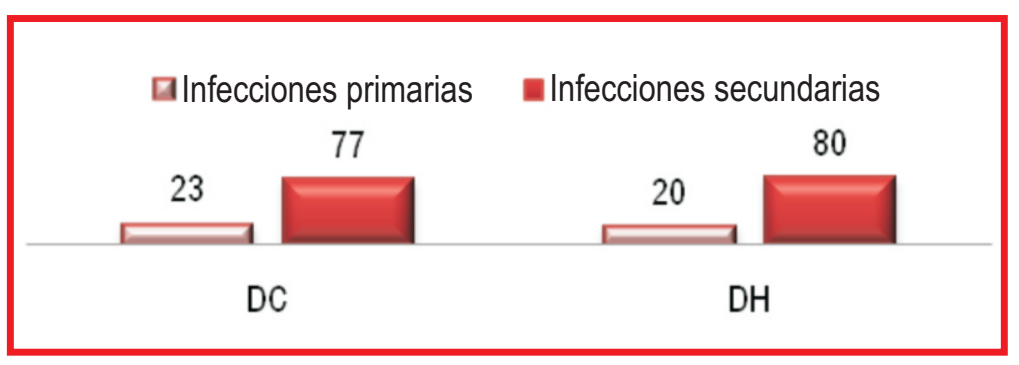




\section{Determinación de los polimorfismos}

\section{Variante DC-SIGN1-336}

Después de hacer un PCR alelo específico, se obtuvo el fragmento de interés de $150 \mathrm{pb}$, se procedió a la purificación de los productos con un kit de purificación comercial, GFX ${ }^{\mathrm{TM}}$ PCR DNA and Gel Band Purification Kit (illustra ${ }^{\mathrm{TM}}$, GE Healthcare, UK) y luego se determinaron los genotipos por medio de la digestión con la enzima de restricción Mscl, posteriormente, a través de una electroforesis en geles de agarosa, se observaron las diferentes bandas como se muestra en la imagen 1. La resolución de los resultados por PCR-RFLP fue bastante alta. Se encontró una concordancia del $100 \%$ entre las técnica de PCR-RFLPe iPLEX.

Imagen 1. Polimorfismo de la variante DC-SIGN1-336, con la enzima de restricción Mscl. A: amplificación por PCR 150pb. B: genotipo GG; 1 bandas de $131 \mathrm{pb}$, genotipo AG; 2 bandas de 150,131pb, genotipo AA; 1 banda de $150 \mathrm{pb}$
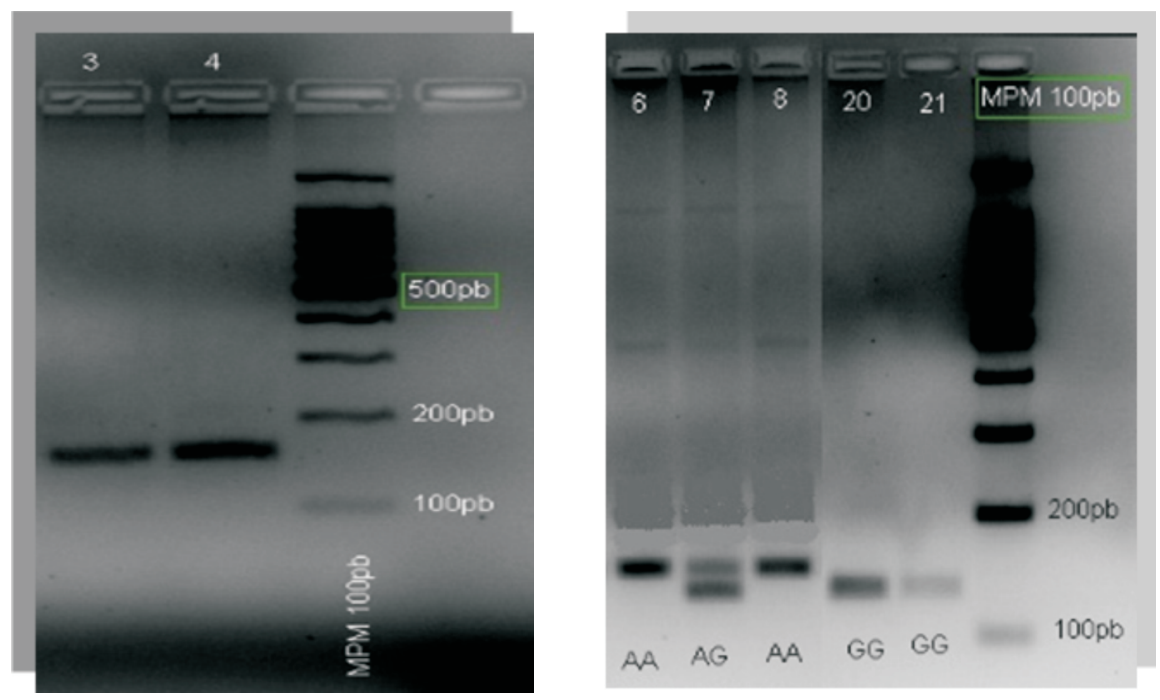

\section{Variante FcyRIIA-131 H/R}

Después de obtenido el fragmento de $366 \mathrm{pb}$, posterior al PCR que utiliza iniciadores específicos para el segmento de interés, este se purificó y se procedió a realizar el corte con la enzima de restricción BstUl. Los resultados de la electroforesis después de la digestión enzimática se observan en la imagen 2. 
Imagen 2. Polimorfismo de la variante FcyRIIA-131 H/R con la enzima de restricción BstUI. A: amplificación por PCR 366pb. B Genotipo RR (CC); 1 banda de 322pb, genotipo RH (TC); 2 bandas de 322 y 343pb, genotipo HH (TT); 1 banda de 343pb.

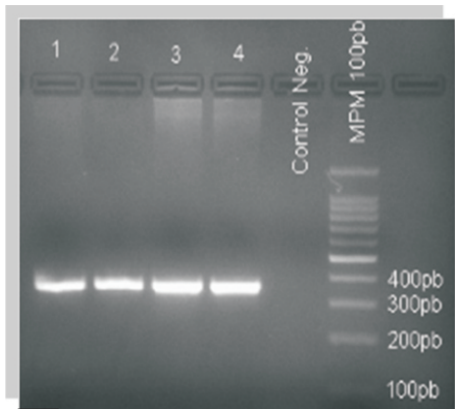

A

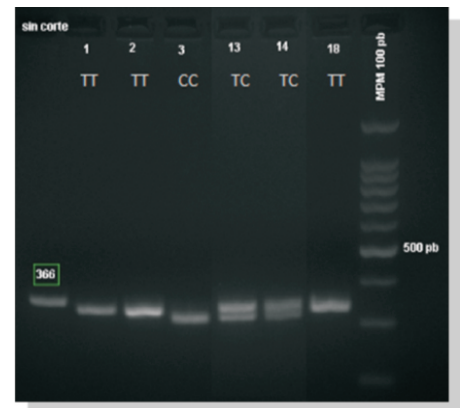

$\mathrm{B}$

Se observó una concordancia del $93 \%$ en los resultados entre las dos técnicas (PCR-RFLP versus iPLEX). De acuerdo con los análisis por MassArrays (iPLEX), en las muestras en las que no se encontró concordancia pertenecen al genotipo CC, pero en el RFLP se observaron como TC oTT.

\section{Variante VDR-352}

Para la variante VDR-352 el producto de amplificación esperado fue de 745pb, el cual fue digerido con la enzima de restricción Taq II, el patrón de restricción se observa en la imagen 3.

Imagen 3. Polimorfismo de la variante VDR-352, con la enzima de restricción Taq ${ }^{\mathrm{a}}$ I. A: amplificación por PCR 745pb. B: Genotipo TT, 2 bandas 494 y $251 \mathrm{pb}$, genotipo TC, 4 bandas 494, 293, 251, 201pb, genotipo CC, 3 bandas $293,251,201 \mathrm{pb}$
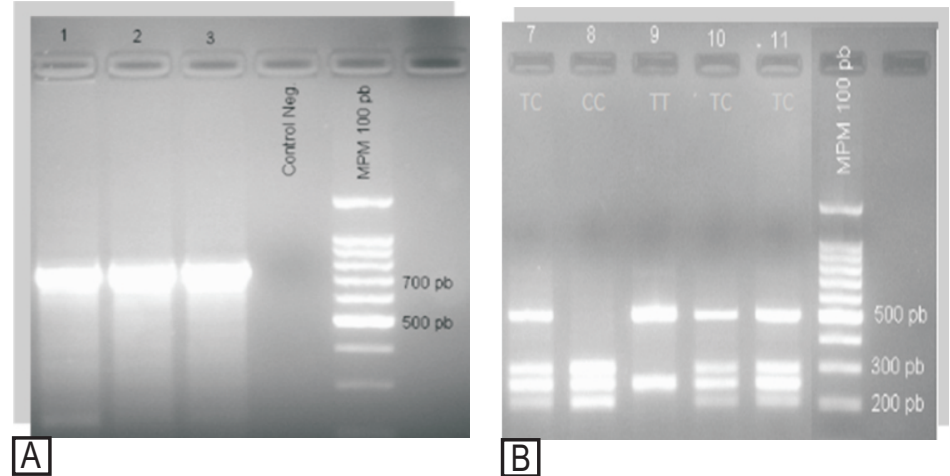
Para este polimorfismo se encontró concordancia del $100 \%$ en los resultados de las dos técnicas, obteniéndose bandas de alta resolución para la diferenciación de los genotipos resultantes. Estas bandas son claramente distinguibles por medio de la técnica de RFLP implementada.

En resumen (tabla 1), se observó un aumento significativo de mayor riesgo de padecer un dengue severo en los portadores de los genotipos CT versus CC de FcyRIIA-131, $\left(\mathrm{Chi}^{2}=5.29, \mathrm{P}=0.02, \mathrm{OR}=2.22\right)$. El alelo $\mathrm{G}$ de la variante $\mathrm{DC}-\mathrm{SIGN1}$ 336 no se asoció con el dengue severo.

El análisis de las frecuencias del genotipo CC en comparación con el genotipo TC de VDR-352, mostró una tendencia a aumentar en las formas severas respecto a las formas leves de la enfermedad $\left(\mathrm{Chi}^{2}=3.36, \mathrm{P}=0.06, \mathrm{OR}=0.35\right)$

Tabla 1. Frecuencia de los polimorfismos en los genotipos del DC-SIGN1-336, FcyRIIA-131 H/R y VDR-352, en los casos y los controles

\begin{tabular}{|c|c|c|c|c|c|c|c|c|}
\hline \multicolumn{3}{|c|}{$\begin{array}{c}\text { Frecuencia de los } \\
\text { polimorfismos }\end{array}$} & \multicolumn{3}{|c|}{ DF vrs DHF } & X2 & \multirow{2}{*}{\begin{tabular}{|c|} 
OR $(95 \%$ IC) \\
$0.76(0.42-1.37)$ \\
\end{tabular}} & \multirow{2}{*}{$\begin{array}{c}\text { valor } p \\
0.36\end{array}$} \\
\hline \multirow{9}{*}{$\begin{array}{l}1 \text { DC-SIGN (A/G) } \\
\text { DC } \\
\text { DH }\end{array}$} & \multirow{9}{*}{$\begin{array}{l}\text { GG } \\
3 \\
3\end{array}$} & \multirow{9}{*}{$\begin{array}{cc}\text { GA } & \text { AA } \\
32 & 62 \\
27 & 70\end{array}$} & Genotipo & \multicolumn{2}{|c|}{$C O+C \wedge A \Lambda$} & 0.82 & & \\
\hline & & & $\mathrm{DC}$ & 35 & 62 & & & \\
\hline & & & $\mathrm{DH}$ & 30 & 70 & & & \\
\hline & & & Genotipo & $\mathrm{GA}$ & $\mathrm{AA}$ & 0.86 & $0.75(0.41-1.38)$ & 0.35 \\
\hline & & & DC & 32 & 62 & & & \\
\hline & & & $\mathrm{DH}$ & 27 & 70 & & & \\
\hline & & & Genotipo & GG & $\mathrm{AA}$ & 0.02 & $0.89(0.19-4.05)$ & 0.88 \\
\hline & & & DC & 3 & 62 & & & \\
\hline & & & $\mathrm{DH}$ & 3 & 70 & & & \\
\hline 2 FcyRIIA (T/C) & TT & TC CC & Genotipo & TC & $\mathrm{CC}$ & 5.29 & $2.22(1.12-4.37)$ & 0.02 \\
\hline DC & 16 & $39 \quad 33$ & $\mathrm{DC}$ & 39 & 33 & & & \\
\hline $\mathrm{DH}$ & 17 & $55 \quad 21$ & $\mathrm{DH}$ & 55 & 21 & & & \\
\hline & & & Genotipo & TT & $\mathrm{CC}$ & 1.33 & $1.67(0.70-3.96)$ & 0.24 \\
\hline & & & $\mathrm{DC}$ & 16 & 33 & & & \\
\hline & & & $\mathrm{DH}$ & 17 & 21 & & & \\
\hline $3 \operatorname{VDR}(\mathrm{T} / \mathrm{C})$ & TT & $\mathrm{TC}$ CC & Genotipo & TT & $\mathrm{CC}$ & 2.05 & $0.45(0.15-1.32)$ & 0.15 \\
\hline $\mathrm{DC}$ & 50 & $40 \quad 5$ & DC & 50 & 33 & & & \\
\hline $\mathrm{DH}$ & 54 & 3412 & $\mathrm{DH}$ & 54 & 21 & & & \\
\hline & & & Genotipo & $\mathrm{TC}$ & $\mathrm{CC}$ & 3.36 & $0.35(0.12-1.06)$ & 0.06 \\
\hline & & & $D C$ & 40 & 5 & & & \\
\hline & & & $\mathrm{DH}$ & 34 & 12 & & & \\
\hline
\end{tabular}




\section{DISCUSIÓN}

Honduras se considera un país endémico por dengue por las casi dos décadas de reporte continuo del mismo, presentando epidemias cíclicas altamente significativas. La frecuencia global de infecciones secundarias en el estudio fue de un $78 \%(n=200)$, con frecuencias muy similares de casos de DC y DH en infecciones primarias, aún existe alrededor de un $20 \%$ de casos severos de dengue en infecciones primarias. Esto permite pensar que no se puede atribuir totalmente la ocurrencia de los casos de DH a una mayor proporción de infecciones secundarias, como ha sido propuesto.

Las células dendríticas son las principales células blancas del virus del dengue in vivo por ser residentes normales de la piel. La proteína (receptor de lectina tipo C) DC-SIGN codificada en la región CD209 localizado en el cromosoma 19. Esta lectina interactúa con fracciones de glicanos de la proteína $E$ del virus del dengue y media la entrada de los cuatro serotipos a la célula. Los compuestos de glicanosmanosa añadido por las células de los insectos a la proteína $E$, parece ser crítica para que DC-SIGN1-336 medie la entrada viral. Este receptor puede conferir susceptibilidad al dengue en células que normalmente no son permisivas, como las células dendríticas y de langerhans presentes en la piel.

En un estudio en población tailandesa se evaluó el efecto de una variante en el promotor del CD209, DC-SIGN1-336, en donde se reportó que el alelo G (GGoAG) de la variante DC-SIGN1-336 resultó ser poco frecuente (2\%) en 150 personas con DC en comparación con 693 controles (12\%) (OR 0.20, IC 95\%:0.08 a 0.44, $\left.P<10^{-4}\right)$. En este mismo estudio no se observó ningún efecto protector en el dengue hemorrágico (OR 1.19, IC 95 \%: 0.88 a 1.61, $P=0,24$ ). Sin embargo, el alelo $G$ se asoció significativamente con el riesgo de dengue hemorrágico $(n=150)$ cuando los casos de dengue hemorrágico fueron comparados con los del dengue clásico (OR 5.88, IC $95 \%$ : 2.56 a $\left.15.33, P=1.4 \times 10^{-7}\right)$ [19].

En el presente estudio, el alelo G de la variante de DC-SIGN1-336 no se asoció con las formas de dengue severo, como se reportó anteriormente en el estudio tailandés, pero esto concuerda con otro estudio realizado en Brasil, en donde no se encontró asociación de este SNP con el dengue hemorrágico. El receptor Fcyll es un receptor ampliamente distribuido en todas las subclases de lgG, puede mediar el $A D A$ in vitro mediante la unión a los complejos virus-lgG . La sustitución de una arginina por histidina en la posición 131 del gen FcyRll se ha asociado con enfermedad meningocócica e infecciones respiratorias recurrentes. Este polimorfismo cambia la afinidad de unión del receptor lgG, lo que reduce la 
capacidad de opsonización de los anticuerpos lgG2 asociado causalmente con la variante arginina. Loke y colaboradores, compararon homocigotos de la variante arginina en 302 casos de SCD (6\%) y 238 controles sanos en Vietnam (11\%). Aunque el resultado no fue estadísticamente significativo, OR 0.57, IC $95 \%$ : 0.29 $1.11, P=0.07$, el intervalo de confianza no descarta un efecto protector potencialmente importante.

En el presente estudio se encontró un mayor riesgo, el cual es significativo en los portadores de los genotipos TC de FcyRIIA (X2 = 5.29, $p=0.02, \mathrm{OR}=2.22$ ) (cuadro 2), de acuerdo con los resultados de Loke, la función biológica de los receptores de Fc en el dengue es de especial importancia por su papel del receptor para ligar lgG2 humana y, posteriormente, su función en la respuesta inmunológica. El receptor de la vitamina $D$ (VDR) interviene en los efectos inmunoregulatorios de 1,25hidroxivitamina D3 (1,25 D3) que activa los monocitos, estimulando la respuesta inmune celular, la producción de inmunoglobulinas y la supresión de la proliferación de linfocitos. El alelo $C$ de un SNP en la posición 352 del gen VDR se ha asociado con resistencia a la lepra tuberculoide e infección por hepatitis $B$.

La expresión de VDR puede afectar la susceptibilidad al dengue hemorrágico, ya que activa los linfocitos B y T que expresen VDR y 1,25 D3 afecta a los monocitos, el sitio principal de infección y replicación del dengue. El alelo T en la posición 352 del gen del receptor de vitamina $\mathrm{D}$ (VDR) se ha asociado con la resistencia a los casos severos de dengue, aunque el mecanismo exacto necesita ser explorado. En nuestro estudio, encontramos que al comparar las frecuencias de los genotipos CC versus TC se observa una tendencia al aumento con las formas graves comparado con las presentaciones clínicas leves de la infección por dengue; $X 2=3.36, p=0.06$ yOR $=0.35$.

Además, se comparó la técnica de PCR-RFLP con la técnica de referencia ¡PLEX (Massarray), con el fin de determinar la concordancia entre estas dos técnicas. La tecnología para el desarrollo del Massarray es sumamente costosa, además requiere de equipo especializado y sofisticado. En cambio, la PCR-RFLP ha sido una de las primeras técnicas utilizadas para determinar huellas génicas, mucho tiempo antes que las técnicas de genotipificación de última generación y, a pesar de ser una técnica bastante laboriosa, es mucho menos costosa y puede ser, por ende, más accesible, además posee una alta reproducibilidad, obteniéndose buenos resultados en la comparación con otras tecnologías de punta. En este estudio se obtuvo una concordancia global de los tres polimorfismos del $97.6 \%$, posicionándola como un excelente candidato para su uso e implementación en laboratorios con requerimientos de tecnología básicos para hacer PCR. 


\section{CONCLUSIONES}

Se observó un alto porcentaje de infecciones secundarias (78 \%), como era de esperarse en zonas endémicas; igualmente, se encontró la frecuencia de infecciones secundarias en dengue clásico (controles) y hemorrágico (casos), prácticamente en las mismas proporciones. Estos hallazgos favorecen las hipótesis de que existen otros factores que inciden en el desencadenamiento de las infecciones por dengue, tanto del vector como del hospedero, las cuales deben ser consideradas y exploradas con mayor detalle y en diferentes escenarios.

Estos datos preliminares aportan nuevos conocimientos sobre el papel de los factores genéticos en la enfermedad del dengue en pacientes hondureños, el aumento en el número de polimorfismos que están asociados a protección o susceptibilidad al dengue severo, proporcionarían información valiosa sobre los posibles mecanismos de patogénesis y protección.

En ausencia de evidencia concluyente sobre el rol que juega el vector, el virus y el huésped en la patogénesis del dengue, algunos marcadores de severidad pueden resultar ser una herramienta útil como indicadores de pronóstico en dengue y otras enfermedades (infecciosas y no infecciosas).

En el futuro, se espera conducir más estudios de los polimorfismos en nuestra población hondureña que permitan asociarlos a la patogenia en los pacientes infectados con el virus del dengue y que estos permitan predecir 0 , al menos, sugerir sobre el potencial de gravedad de la infección y conducir a un mejor manejo clínico.

\section{AGRADECIMIENTOS}

Nuestro agradecimiento al equipo de trabajo de la Sección de Virología de la Universidad Nacional Autónoma de Honduras y al Programa Teasdale-Corti Honduras-Canadá, 2007-2012, Fortaleciendo capacidades para lograr la meta No. 6 del milenio en Honduras: combatiendo las enfermedades infecciosas.

\section{BIBLIOGRAFÍA}

Bellamy, R. et al. (1999). Tuberculosis and chronic hepatitis B virus infection in Africans and variation in the vitamin D receptor gene. J Infect Dis, 179(3), pp. $721-4$. 
Cooke, G.S. and Hill, A.V. (2001). Genetics of susceptibility to human infectious disease. Nat Rev Genet, 2(12), pp. 967-77.

Fijen, C.A., Bredius, R.G. and Kuijper, E.J. (1993). Polymorphism of IgG Fc receptors in meningococcal disease. Ann Intern Med, 119(7 Pt 1), pp. 636.

Gubler, D.J. (1998). Dengue and dengue hemorrhagic fever. Clin Microbiol Rev, 11(3), pp. 480-96.

Gubler, D.J. and Trent, D.W. (1993). Emergence of epidemic dengue/dengue hemorrhagic fever as a public health problem in the Americas. InfectAgents Dis, 2(6), pp. 383-93.

Guzman, M.G. et al. (1990). Dengue hemorrhagic fever in Cuba, 1981: a retrospective seroepidemiologic study. Am J Trop Med Hyg, 42(2), pp. 179-84.

Halstead, S.B. (1979). In vivo enhancement of dengue virus infection in rhesus monkeys by passively transferred antibody. J Infect Dis, 140(4), pp. 527-33.

Huang, Y.W. et al. (2010). Vitamin D receptor gene polymorphisms and distinct clinical phenotypes of hepatitis B carriers in Taiwan. Genes Immun, 11(1), pp. 8793.

Kurane, I. (2007). Dengue hemorrhagic fever with special emphasis on immunopathogenesis. Comp Immunol Microbiol Infect Dis, 30(5-6), pp. 329-40.

Littaua, R., Kurane, I. and Ennis, F.A. (1990). Human IgG Fc receptor II mediates antibody-dependent enhancement of dengue virus infection. J Immunol, 144(8), pp. 3183-6.

Loke, H. et al. (2002). Susceptibility to dengue hemorrhagic fever in vietnam: evidence of an association with variation in the vitamin d receptor and Fc gamma receptor lla genes. Am J Trop Med Hyg, 67(1), pp. 102-6.

Malavige, G.N. et al. (2011). HLA class I and class II associations in dengue viral infections in a Sri Lankan population. PLoS One, 6(6), pp. e20581.

Neves-Souza, P.C. et al. (2005). Inducible nitric oxide synthase (iNOS) expression in monocytes during acute Dengue Fever in patients and during in vitro infection. BMC InfectDis, 5, pp. 64.

Pokidysheva, E. et al. (2006). Cryo-EM reconstruction of dengue virus in complex with the carbohydrate recognition domain of DC-SIGN. Cell, 124(3), pp. 485-93.

Roy, S. et al. (1999). Association of vitamin D receptor genotype with leprosy type. J Infect Dis, 179(1), pp. 187-91.

Rothman, A.L. and Ennis, F.A. (1999). Immunopathogenesis of Dengue hemorrhagic fever. Virology, 257(1), pp. 1-6.

Sanders, L.A. et al. (1994). Fc gamma receptor lla (CD32) heterogeneity in patients with recurrent bacterial respiratory tract infections. J Infect Dis, 170(4), pp. 85461.

Sangkawibha, N. et al. (1984). Risk factors in dengue shock syndrome: a prospective epidemiologic study in Rayong, Thailand. I. The 1980 outbreak. Am J Epidemiol, 
120(5), pp. 653-69.

Sakuntabhai, A. et al. (2005). A variant in the CD209 promoter is associated with severity of dengue disease. Nat Genet, 37(5), pp. 507-13.

Sierra, B.; Kouri, G. and Guzman, M.G. (2007). Race: a risk factor for dengue hemorrhagic fever. Arch Virol, 152(3), pp. 533-42.

Sierra, B. et al. (2007). HLA-A, -B, -C, and -DRB1 allele frequencies in Cuban individuals with antecedents of dengue 2 disease: advantages of the Cuban population for HLA studies of dengue virus infection. Hum Immunol, 68(6), pp. $531-40$.

Silva, L.K. et al. (2010). Dengue hemorrhagic fever is associated with polymorphisms in JAK1. Eur J Hum Genet, 18(11), pp. 1221-7.

Van de Winkel, J.G. and Capel, P.J. (1993). Human IgG Fc receptor heterogeneity: molecular aspects and clinical implications. Immunol Today, 14(5), pp. 215-21.

Who, W.H.O. (2009). Dengue: guidelines for diagnosis, treatment, prevention and control.

Who, W.H.O. (2009). Dengue and dengue haemorrhagic fever.

Wu, S.J. et al. (2000). Human skin Langerhans cells are targets of dengue virus infection. NatMed, 6(7), pp. 816-20. 